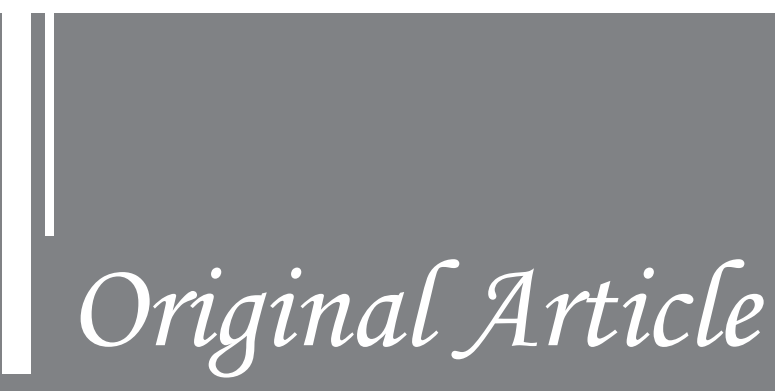

\title{
PERCEPTIONS OF ANTENATAL CARE PROVIDERS ABOUT ORAL HEALTH OF PREGNANT WOMEN AT THE HOSPITALS OF KARACHI
}

\author{
Ayesha Ayaz', Sheh Mureed ${ }^{2}$, Zubair Ahmed Abbasi ${ }^{3}$, Neelofar Ayaz \\ Naveen Farooq ${ }^{3}$, Sahar $^{4}$
}

'student at the Health Services Academy Islamabad

${ }^{2}$ Assistant Professor, Health Services Academy Islamabad

${ }^{3}$ Consultant Dental \& Maxillofacial Surgeon, Jinnah Sindh Medical University Karachi

${ }^{3}$ Consultant Obstetrician \& Gynaecologist, Al-Khidmat Hospital Nazimabad Karachi

${ }^{3}$ student at Health Services Academy Islamabad

${ }^{4}$ student at Health Services Academy Islamabad

Correspondence:Ayesha Ayaz. Email: ayesha_ayaz@live.com

\begin{abstract}
Background: WHO has recommended a positive pregnancy experience for a healthy mother and her newborn and for achievement of positive motherhood. Oral disease of the mother during pregnancy is an important public health issue due to its prevalence and life course connections with adverse pregnancy outcomes.

Methods: A cross-sectional study was conducted of 200 ANC providers and questionnaires were filled by 100 obstetricians, 65 medical officers and 35 post graduate trainees practicing in gynecological department in twenty hospitals of Karachi.

Results: The results indicated insufficient knowledge among ANC providers about effect of poor maternal oral health on pregnancy and birth consequences. Majority of the participants agreed on importance of oral health during pregnancy even minority was engaged in discussing the importance of dental care or referring them to a dental surgeon. Those participants who had more knowledge about oral health during pregnancy were also seen engaged with their practices.

Conclusion: The findings indicate that in Karachi ANC providers are not well knowledgeable about maternal oral health. The main reasons may be lack of practices guidelines in oral health care during pregnancy, no refresher courses for ANC providers keep them updated. ANC providers seem cooperative to discuss oral health if they are having adequate knowledge in this domain.

Keywords: ANC providers, oral health, pregnant women, pregnancy, dentists and dental care
\end{abstract}




\section{Introduction}

From the 20th century Antenatal care (ANC) is now practiced as a routine all over the world and most of the developed countries have this program on the basis of individual consultancy with a midwife or a doctor. There is a keen interest among women in seeking of ANC which provides them a physical condition of their health and development of their fetus(1).

A good opportunity has been provided by the ANC providers in order to upgrade maternal perception regarding pregnancy, childbirth and he care of newborn. "The World Health Organization's (WHO) focused ANC model recommends information and counseling be provided to all pregnant women in areas related to the health needs of the pregnant woman"(2). The WHO has now proposed recommendations on ANC for a positive pregnancy experience. These are very important guidelines but unfortunately these are not being implemented in Pakistan yet. The main difference is that WHO focused ANC model endorsed that it is a right of every pregnant women that she must be provided with all the relevant information while WHO recommendations for a positive pregnancy experience recommends that quality care throughout pregnancy, parturition and postpartum should be received by every expecting mother and her baby. "Within the continuum of reproductive health care, ANC provides a platform for important health-care functions, including health promotion, screening and diagnosis, and disease prevention. The WHO Technical Consultations led to the development of 39 recommendations related to five types of interventions: A. Nutritional interventions, B. Maternal and fetal assessment, C. Preventive measures, D. Interventions for common physiological symptoms, and E. Health system interventions to improve utilization and quality of ANC"(3)

Pregnancy is an exclusive time period in the life of every woman because it is responsible to bring noticeable changes in the oral cavity due to complex physiological alterations in the body(4). The interest has been increasing regarding oral health of pregnant patients during the last few years(5)."The American Dental Association, the American Congress of Obstetricians and Gynecologists and the American Academy of Pediatrics all encourage women to get dental care while pregnant. It is a crucial period of time in a woman's life and maintaining oral health is directly related to good overall health," says Aharon Hagai, D.M.D(6). Pregnancy is an exclusively important in the oral health promotion because of its complex physiologic changes occurring throughout the pregnancy which are responsible for fluctuations in progesterone and estrogen level(7).There is high incidence of dental caries due to increased food craving in pregnancy which leads to food consumption rich in carbohydrates(8).It is mandatory for health care professionals to capable enough to guide their patients effectively regarding health issues which are common primarily(9).

The purpose of this study was to assess the knowledge, attitude, practices of ANC providers about oral health of pregnant women in the hospitals of Karachi and to determine the association between sociodemographics, knowledge, attitude and barriers with practices. This may contribute in the establishment of prescribed guidelines regarding maternal oral health.

\section{Methodology}

The study design was cross sectional with quantitative design. Study was conducted in twenty hospitals of Karachi where ANC was being provided. The time period for the study was three months. Data sources were primary data collection from the ANC providers. A structured questionnaire was distributed among the participants. To recruit the participants for the study, purposive sampling technique was applied. Sample from the ANC providers was collected in the time period of one month. All health care professionals who were providing ANC to the patients included in the study like obstetricians and gynecologists, post graduate trainees and resident medical officers posted in gynecological department only. Those ANC providers who were out of practice and those house officers posted in gynecological department at that time were excluded from the study. A structured questionnaire was being filled by the ANC providers. A pre-existing questionnaire from a study was adapted with minor changes (10). The tools consisted of five sections. Section-one was of about socio-demographic features of the ANC providers. Section-two had 28 questions regarding knowledge. Section-three had 16 questions about attitude. Section-four had 13 questions about their routine practices. And the last section was comprised of 11 questions about the barriers being faced by ANC providers about oral health of expecting mothers in the hospitals of Karachi. Data collection tool was pilot tested on 15 participants before data collection procedure. To assure the reliability of the data, pilot testing was being carried out. For the assurance of validity, it has been used in the past study conducted in Australia (10)

Data collected from the questionnaire was imported to SPSS version 21.0 and analyzed in the same software. The responses to the structured questionnaire were analyzed descriptively. Descriptive results are shown in proportion, percentages, frequencies, mean, median, mode and standard deviation. Data was also analyzed through inferential statistics through chi square. Results are displayed in the form of tables, graphs and charts. Data was collected after approval by Institutional Review Board of Health Services Academy, Islamabad. Informed written consent was taken from all the participants. Anonymity of the participants was kept strictly confidential. Confidentiality and privacy of the data was maintained properly.

\section{Results}

Total of 200 participants were being selected to be included in the study. Their response has been shown through different tables. In Table 1 the socio-demographic characteristics of ANC providers have been shown. All the participants were females. Majority of the participants fell into the category of 41-50 years of age. Few were in the range between 51-60. Half of the respondents were obstetrician and gynaecologists. Others were resident medical officers and post graduate trainees. The ANC providers were equally distributed among public and private sector. Most of the ANC providers used to work 3140 hours per week. Only 3 out of 200 used to work 1-10 hours per week. Fifty percent of the ANC providers had qualified for post-graduation while $50 \%$ were simply graduated. Average years of experience of majority of the ANC providers were up to 20 years. Only one ANC provider had experience above 40 years. Location of practice of majority of the participants was District Central Karachi.

Table1: Socio-demographic characteristics of ANC providers (Total $\mathbf{n}=\mathbf{2 0 0}$ )

\begin{tabular}{|l|c|c|}
\hline Variable & Frequency & Percentage \\
\hline Age in years & 35 & 17.5 \\
\hline Up to 30 & 55 & 27.5 \\
\hline $31-40$ & 77 & 38.5 \\
\hline $41-50$ & 15 & 7.5 \\
\hline 51 to 60 & 18 & 9.0 \\
\hline above 60 & & \\
\hline Main Role in Employment & 100 & 50.0 \\
\hline O \& G & 65 & 32.5 \\
\hline R.M.O. & 35 & 17.5 \\
\hline P.G. Trainee & & 50.0 \\
\hline Main Area of Practice & 100 & 50.0 \\
\hline Government & 100 & \\
\hline Private & & 1.5 \\
\hline Average no. of Hours worked per week & 3 & 15.0 \\
\hline $1-10$ & 30 & 22.0 \\
\hline $11-20$ & 44 & 29.0 \\
\hline $21-30$ & 58 & 12.0 \\
\hline $31-40$ & 24 & 16.0 \\
\hline $41-50$ & 16 & \\
\hline $51-60$ & 50 & \\
\hline$>60$ & & \\
\hline Highest Qualification Obtained & & \\
\hline F.C.P.S. & & \\
\hline & & \\
\hline
\end{tabular}

In table 2 characteristics of ANC providers regarding oral health care during pregnancy are shown. According to the table, most of the ANC providers usually came across 1-5 pregnant women with oral health problems per week. Majority of the ANC providers used to refer the pregnant women to the dentists. Only $5(2.5 \%)$ of the ANC providers had received training on oral health care during pregnancy. Majority $195(97.5 \%)$ had not received any training. Very few of them had information or brochures regarding oral health care during pregnancy in their practice. 
Table 2: Characteristics of ANC Providers regarding oral health care during pregnancy $(n=200)$

\begin{tabular}{|l|c|c|}
\hline Variable & Frequency & Percentage \\
\hline $\begin{array}{l}\text { Average no. of pregnant women seen per week with oral } \\
\text { health problems }\end{array}$ & 20 & 10.0 \\
\hline none & 141 & 70.5 \\
\hline $1-5$ & 17 & 8.5 \\
\hline $6-10$ & 22 & 11.0 \\
\hline$>10$ & & \\
\hline $\begin{array}{l}\text { Average no. of dental referrals you would give to pregnant } \\
\text { women per week }\end{array}$ & 42 & 21.0 \\
\hline None & 158 & 79.0 \\
\hline $1-5$ & 5 & 2.5 \\
\hline Any training received on oral health care during pregnancy & 195 & 97.5 \\
\hline Yes & & \\
\hline No & 10 & 5.0 \\
\hline $\begin{array}{l}\text { Any brochures on oral health during pregnancy in your } \\
\text { practice }\end{array}$ & 190 & 95.0 \\
\hline Yes & & \\
\hline No & & \\
\hline
\end{tabular}

According to the above table 3 it is shown that most participants in spite of being less knowledgeable $(70 \%)$, even though, they had positive attitude towards oral health care (88\%) during pregnancy. Practices level of majority of them was observed as moderate $(76 \%)$.

Table 3: Levels of Knowledge, Attitude and Practices $(n=200)$

\begin{tabular}{|l|c|c|}
\hline Knowledge level & $\mathbf{n}$ & $\%$ \\
\hline High knowledge (28-42) & 60 & 30 \\
\hline Low Knowledge (43-84) & 140 & 70 \\
\hline Mean \pm SD, Min- Max & \multicolumn{2}{|c|}{$45.91 \pm 7.42,32-73$} \\
\hline Attitude Level & 176 & 88 \\
\hline Positive Attitude (16-40) & 24 & 12 \\
\hline Negative Attitude (41-80) & \multicolumn{2}{|c|}{$31.5 \pm 7.18,19-52$} \\
\hline Mean \pm SD, Min- Max & 14 & 7 \\
\hline Practices level & 152 & 76 \\
\hline Good practices (up to 19) & 34 & 17 \\
\hline Moderate practices (20-32) & \multicolumn{2}{|c|}{$27.1 \pm 5.21,19-39$} \\
\hline Bad practice (33onwards) & \multicolumn{2}{|c|}{} \\
\hline Mean \pm SD, Min- Max & \multicolumn{2}{|c|}{} \\
\hline
\end{tabular}

In table 4 statistically significant associations have been shown in between socio-demographics, knowledge and attitude with practices According to the table, the sociodemographic factors which had statistically significant association with practices were age, role in employment, average no. of hours worked per week, highest qualification obtained, average no. of pregnant women seen per week with oral health problems, average no. of dental referrals they had given to pregnant women per week, any training received on oral health care during pregnancy and any brochures having on oral health during pregnancy in their practice. Moreover, knowledge as well as attitude levels were also had statistically significant association with practices.
Table 4: Association of Socio-demographics, Knowledge \& Attitude with Practices were found out through chi square test. $(\mathbf{n}=\mathbf{2 0 0})$

\begin{tabular}{|c|c|}
\hline Variables & p-value \\
\hline \multicolumn{2}{|l|}{ Socio demographics } \\
\hline Age in years & $<0.001$ \\
\hline Area of practice & 0.115 \\
\hline Role in employment & $<0.001$ \\
\hline Average no. of hours worked per week & $<0.001$ \\
\hline Highest Qualification Obtained & $<0.001$ \\
\hline Average years of experience & 0.060 \\
\hline Location of Practice & 0.857 \\
\hline $\begin{array}{l}\text { Average no. of pregnant women seen per week with oral health } \\
\text { problems }\end{array}$ & 0.003 \\
\hline $\begin{array}{l}\text { Average no. of dental referrals you would give to pregnant } \\
\text { women per week }\end{array}$ & 0.006 \\
\hline Any training received on oral health care during pregnancy & 0.011 \\
\hline $\begin{array}{l}\text { Any brochures having on oral health during pregnancy in your } \\
\text { practice }\end{array}$ & $<0.001$ \\
\hline Knowledge level & 0.015 \\
\hline - High Knowledge & \\
\hline - Low Knowledge & \\
\hline Attitude level & 0.001 \\
\hline - Positive attitude & \\
\hline
\end{tabular}

Level of significance at $\mathrm{p}$-value $<0.05$

Frequently faced barriers by most of the ANC providers are presented in the form of bar chart including reluctance among dental professionals to treat pregnant women, patient's lack of concern with oral health care during pregnancy, not sufficiently trained to perform oral health assessments, lack of practices guidelines on oral health care during pregnancy in Pakistan, concern of pregnant women about safety of dental procedures and in the but not the least lack of time for providing advice (figure 1).

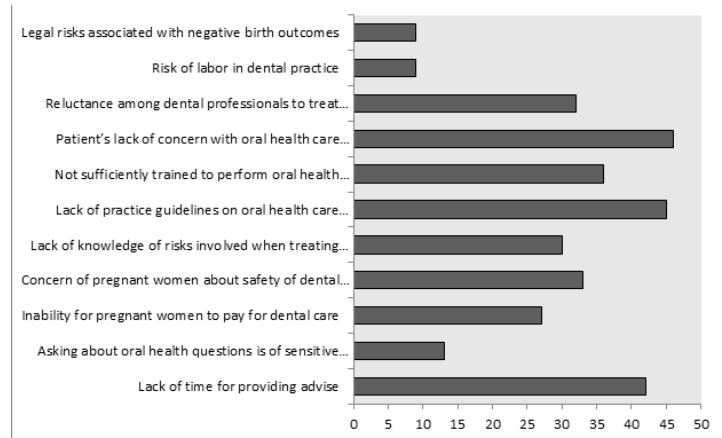

Figure 1: Common barriers faced by ANC providers during their practices

\section{Discussion}

The present study showed that the overall level of knowledge of ANC providers is relatively low. The results of this study reveal that less than half of the respondents are well knowledgeable about the oral health and pregnancy. A study with similar findings was also carried out in Australia which showed that there was limited knowledge among ANC providers(10). Most of the ANC providers are aware that pregnancy do exacerbates existing dental problems and if left untreated will exaggerate further dental problems. Similar findings were also found from a study carried out in United Arab Emirates (UAE) in which majority acknowledged that there is a connection between pregnancy and oral health (11). Few ANC providers have an idea that periodontal diseases do effect on birth outcomes. A study conducted in Australia also acknowledged that poor maternal oral health have also an effect on infant outcome (10). Regarding effect of periodontal disease on birth outcomes, the response was average. These results somehow are similar with the findings that were also indicated from a study 
undertaken in Australia and which clearly showed that half of nurses had knowledge about association between disease of periodontium of mother during pregnancy with low birth weight $(43.6 \%)$ and preterm birth (48.9\%)(13). Maximum ANC providers have correct knowledge that all women during pregnancy should receive preventive dental care and basic dental treatment is safe too. According to three-fourth of the respondents' consideration dental radiographs are unsafe during pregnancy(11). Almost $50 \%$ of the total ANC providers are in favour that women during pregnancy should only receive emergency dental care. According to two thirds of the respondents extraction and the use of local anesthesia during pregnancy are safe. The findings of local anesthesia are similar compared with a study conducted in U.A.E. and according to $60 \%$ administration of local anesthesia considered unsafe during pregnancy (12). Around $50 \%$ of the respondents agree that root canal treatment and scaling are safe during pregnancy. These findings of this study are found close with a similar study conducted in a developed country, which depicted that around half of the respondents had an idea that RCT is safe during pregnancy and more than $50 \%$ of the respondents had good knowledge that scaling is not harmful during pregnancy(10). The overall level of knowledge of ANC providers regarding what medications should be prescribed and what should be avoided during pregnancy was satisfactory. More than fifty percent of the respondents know that first trimester is unsafe and second trimester is safe during pregnancy. Due to organogenesis all treatments must be avoided in the first trimester. End of first trimester till start of third trimester is considered as the safest time period to avail any dental treatment. Few respondents know that third trimester is not suitable for any dental treatment. The reason to treat patients in third trimester is that due to the position of a patient on a dental chair, the inferior vena cave is pressed which leads to decreased circulation of blood resulting in supine hypotension syndrome.

The overall level of attitude of majority of the ANC providers is positive. They give importance on maintenance of oral health during pregnancy. Another study with similar findings indicated that maximum numbers of ANC providers consider that it is important to maintain oral health during pregnancy, these findings are also similar with the three studies conducted in Kingdom of Saudi Arabian countries (14). Most of them agree that if during pregnancy periodontal treatment is carried out, it has positive effects on birth outcomes. This study has similar findings with a study carried out in UAE in which also states that if periodontal diseases are treated it has positive impact on pregnancy outcomes (10).Most of them have consensus on that women during pregnancy will definitely approach for dental care only when they are recommended by their ANC providers. Similarly majority also agree that ANC providers can better counsel expecting mothers than dental surgeons about oral health while few disagree from this statement, according to them dental surgeons are far better to counsel patients. Majority agree that there is a good understanding between obstetricians and dental surgeons about dental care during pregnancy. The reason for not providing advice to pregnant women is their busy practices and there is an insufficiency of time to advise them about dental health at an ANC visit and they also agree that it is due to the financial barrier or cost of dental treatment which might be unaffordable for some patients. A study carried out in Mysore also revealed that dental treatment is quite expensive which prevents pregnant women to avail dental treatment(15). Another study conducted in Bihar (India) which indicated that almost half $(52 \%)$ considered a barrier in seeking oral health care and that was basically lack of insurance.(16). Most of the ANC providers shows positive attitude regarding desire and interested for further education and information. They also highly recommend that there is a requirement of universally accepted guidelines for oral health care during pregnancy not only for ANC providers but for all health professionals. Oral health care should be incorporated at the level of undergraduate studies. The willingness and positive attitude towards oral health and pregnancy is also obvious from a study carried out in 2016(10).

Practices were found dependent on knowledge, only those ANC providers who had sufficient knowledge were found engaged with good practices. Majority of the ANC providers sometimes discuss on importance of oral health care with patients during pregnancy due to their busy schedules and sometimes provided counseling about relation of bad periodontal health and its negative effects on birth outcomes and caries prevention. Majority of the ANC providers always advise to receive routine checkup and scaling during pregnancy. Most of them never advise their patients to have periodontal treatment whereas fillings and crowns is sometimes advised by some participants. Many of the ANC providers follow up their patients next time which were being referred to dentists at their earlier visit and half of the ANC providers sometimes ask about current oral health of their patients whereas there is also a group who never asks about it due lack of time or maybe they do not consider it as important to be discussed. Carrying out of a visual examination of oral cavity of expecting mothers as part of ANC is practiced sometimes by few ANC providers whereas few are the participants who never carry out the examination of oral cavity may be they consider it as outside of their O\&G practice. If there is any problem identified in pregnant women then majority of the ANC providers refer them to dentists for further evaluation. Similar findings were also reported in study conducted in developed country $(10)$.

The most important barrier which was being faced by ANC providers was lack of practice guidelines on oral health care during pregnancy in Pakistan. The other main barriers which were frequently faced by them were lack of time for providing advice, patient's lack of concern with dental care during pregnancy, hesitation among dental professionals to give treatment to pregnant women and the last but not the least they were not trained enough to conduct oral health assessments. Majority of the ANC providers were not sure whether is there any risk of labour involved while treating pregnant women and the association of regal risks with negative birth outcomes. These findings were also close to the findings of study conducted in Australia(10).Barriers that are faced by ANC providers regarding maternal oral health have an effect that influences practices. Nine out of eleven barriers are significantly associated with the practices.

In socio demographic characteristics age in years, role in employment, average no. of hours worked per week, highest qualification obtained, average no. of pregnant women seen every week with oral health issues, training received on oral health care during pregnancy, information regarding oral health care during pregnancy, knowledge and attitude have statistically significant association with the practices. Due to limitation of time non probability sampling technique (purposive) was used to recruit study participants. The results of this study will not be generalizable as it lacks randomization. Due to lack of time more participants could not be included into the study.

\section{Conclusion}

The results of the study suggest that majority of the ANC providers in Karachi city are not well knowledgeable on maternal oral health, although majority of them showed positive attitude and desire towards influence of oral health during pregnancy. Socio-demographic features, knowledge, attitude and barriers had statistically significant association with the practices. The main reasons may be lack of practices guidelines in Pakistan about dental care during pregnancy, no refresher courses for ANC providers to keep them updated. ANC providers seem cooperative to discuss about oral health if they are having adequate knowledge and guidance in this domain.

\section{References}

1. Brock E, Charlton KE, Yeatman H. Identification and evaluation of models of antenatal care in Australia - A review of the evidence. Aust New Zeal J Obstet Gynaecol [Internet]. 2014 Aug [cited 2018 Feb 13];54(4):300-11.

2. Jennings L, Yebadokpo AS, Affo J, Agbogbe M. Antenatal counseling in maternal and newborn care: use of job aids to improve health worker performance and maternal understanding in Benin. BMC Pregnancy Childbirth [Internet]. 2010 Nov 22 [cited 2018 Feb 13];10:75.

3. WHO recommendations on antenatal care for a positive pregnancy experience [Internet]. [cited 2019 Jan 8].

4. Prakash S, Reddy S, Lakshminarayan N. Gynecologists' concerns about oral diseases - A step to interdisciplinary approach. Int J Oral Heal Sci [Internet]. 2014 [cited 2018 Feb 12];4(2):58.

5. Patil S, Thakur R, K M, Paul ST, Gadicherla P. Oral Health Coalition: Knowledge, Attitude, Practice Behaviours among Gynaecologists and Dental Practitioners. J Int oral Heal JIOH [Internet]. $2013 \mathrm{Feb}$ [cited 2018 Feb 12];5(1):8-15.

6. Dental Concerns During Pregnancy - American Dental Association [Internet]. [cited 2018 Feb 13].

7. Gupta R, Gupta N, Patthi B, Goud V, Singla A, Garg A, et al. Oral Care during Pregnancy: Make every Mother and Child Count- A Review. 2012 [cited 2018 Feb 12]; 
8. Enabulele J, Ibhawoh L. Resident obstetricians' awareness of the oral health component in management of nausea and vomiting in pregnancy. BMC Pregnancy Childbirth [Internet]. 2014 Dec 25 [cited 2018 Feb 4];14(1):388.

9. Ahsen NF, Batul SA, Ahmed AN, Imam SZ, Iqbal H, Shamshair $\mathrm{K}$, et al. Developing counseling skills through pre-recorded videos and role play: a pre- and post-intervention study in a Pakistani medical school. BMC Med Educ [Internet]. 2010 Dec 26 [cited 2018 Feb 14];10(1):7.

10. George A, Dahlen HG, Reath J, Ajwani S, Bhole S, Korda A, et al. What do antenatal care providers understand and do about oral health care during pregnancy: a cross-sectional survey in New South Wales, Australia. BMC Pregnancy Childbirth [Internet]. 2016 Dec 1 [cited 2018 Jan 30];16(1):382.

11. Hashim R, Akbar M. Gynecologists' knowledge and attitudes regarding oral health and periodontal disease leading to adverse pregnancy outcomes. J Int Soc Prev Community Dent [Internet]. 2014 Dec [cited 2018 Sep 9];4(Suppl3):S166-72.
12. George A, Dahlen HG, Reath J, Ajwani S, Bhole S, Korda A, et al What do antenatal care providers understand and do about oral health care during pregnancy: a cross-sectional survey in New South Wales, Australia. BMC Pregnancy Childbirth [Internet] 2016 Dec 1 [cited 2017 Dec 14];16(1):382.

13. Sharif S, Saddki N, Yusoff A. Knowledge and Attitude of Medical Nurses toward Oral Health and Oral Health Care of Pregnant Women. Malays J Med Sci [Internet]. 2016 Jan [cited 2017 Dec 14];23(1):63-71.

14. Knowledge, Attitude and Practices of Gynecologists Regarding the Prevention of Oral Diseases in Riyadh City, Saudi Arabia [Internet]. [cited 2018 Sep 9].

15. George A, Johnson M, Duff M, Blinkhorn A, Ajwani S, Bhole S, et al. Maintaining oral health during pregnancy: perceptions of midwives in Southwest Sydney. Collegian [Internet]. 2011 Jun 1 [cited 2018 Feb 6];18(2):71-9.

16. Morgan MA, Crall J, Goldenberg RL, Schulkin J. Oral health during pregnancy. J Matern Fetal Neonatal Med [Internet]. 2009 Sep 27 [cited 2018 Sep 8];22(9):733-9 